\title{
STUDY OF CUTANEOUS MANIFESTATIONS IN THYROID DISORDERS
}

\author{
Jayanthi Bhavya Sindhu1, Kotha Raghupathi Reddy², Gurram Narsimha Rao Netha³, Damarla Sudha Vani ${ }^{4}$
}

${ }^{1}$ Senior Resident, Department of DVL, Gandhi Medical College, Secunderabad.

${ }^{2}$ Assistant Professor, Department of DVL, Gandhi Medical College, Secunderabad.

3 Professor and HOD, Department of DVL, Gandhi Medical College, Secunderabad.

${ }^{4}$ Assistant Professor, Department of DVL, Gandhi Medical College, Secunderabad.

ABSTRACT

\section{BACKGROUND}

Thyroid disorders are known to involve all organ systems of the body, the skin being no exception.

The present study is aimed to study various cutaneous manifestations and see cutaneous manifestations in thyroid disorders and to know various dermatologic associations of thyroid disorders.

\section{MATERIALS AND METHODS}

This is a prospective, observational study conducted over a period of 18 months in Department of DVL in a Tertiary Care Centre. All patients with thyroid abnormality and cutaneous manifestations are included in the study. Detailed clinical examination is done and the findings are recorded.

\section{RESULTS}

Thyroid disorders are more common in females. The most common age group affected by hypothyroidism was 31 - 40 years, hyperthyroidism is 21 - 30 yrs. Weight gain and dry skin were the commonest symptoms among hypothyroid patients and heat intolerance and increased sweating were commonest among hyperthyroid patients. Xerosis and dry, rough, coarse skin among hypothyroid patients; and warm, soft, velvety skin among hyperthyroid were commonest findings. Urticaria was the most common autoimmune association noted among hypothyroid patients.

\section{CONCLUSION}

With our study, it could be concluded that a better understanding complex interaction between skin and thyroid may help us not only to diagnose underlying thyroid abnormality, but also to monitor response of cutaneous features with treatment.

\section{KEYWORDS}

Hypothyroidism, Xerosis, Alopecia, Hyperthyroidism, Urticaria.

HOW TO CITE THIS ARTICLE: Sindhu JB, Reddy KR, Netha GNR, et al. Study of cutaneous manifestations in thyroid disorders. J. Evolution Med. Dent. Sci. 2016;5(104):7673-7679, DOI: 10.14260/jemds/2016/1731

\section{BACKGROUND \\ Thyroid disorders are known to involve all organ systems of the body, the skin being no exception. The association of \\ The present study also tries to outline the most common dermatologically relevant autoimmune associations of thyroid disease.} thyroid disorders with cutaneous manifestations is complex. Both abnormally low and excessively high serum levels of thyroid hormones can alter the appearance and function of human skin and its appendages. The prevalence of cutaneous changes with thyroid disorders varied from $39 \%$ to $100 \%$ in different studies. With such a high prevalence of cutaneous manifestations in thyroid disorders, the present study is aimed to study various cutaneous manifestations and see if cutaneous manifestations aid in early diagnosis and hence treatment of patients with abnormal thyroid function. Most common cause of abnormalities in thyroid function being autoimmune in aetiology show an association with other autoimmune disorders.

Financial or Other, Competing Interest: None.

Submission 22-11-2016, Peer Review 15-12-2016,

Acceptance 22-12-2016, Published 29-12-2016.

Corresponding Author:

Dr. Kotha Raghupathi Reddy,

\# 2-1-15/4,

Near Old Ramalayam,

Nallakunta, Hyderabad-500044,

Telangana State.

E-mail: krrya7@gmail.com

DOI: $10.14260 /$ jemds $/ 2016 / 1731$

\section{Aims and Objectives}

1. To study various cutaneous manifestations of hypothyroidism and hyperthyroidism.

2. To study various dermatologic disorders associated with thyroid disorders.

\section{MATERIALS AND METHODS}

This is a prospective, observational study conducted over a period of 18 months in Department of DVL in a tertiary hospital. All patients with thyroid abnormality and cutaneous manifestations, either presenting to Dermatology OPD or referred from other Departments are included in the study after taking an informed consent. Demographic data of the patients and detailed history was recorded. A complete clinical examination was carried out and findings were noted. Routine investigations like thyroid profile, CBP, blood sugar, RFT, LFT and lipid profile were carried out in all patients. Relevant investigations like skin biopsy if needed were carried out.

\section{RESULTS}

The present study comprised of 90 patients with laboratory proven thyroid abnormality who presented to DVL OPD with dermatological complaints. 


\section{Thyroid Status}

Of these 90 patients $90 \%$ (81) are hypothyroid and 10\% (9) are hyperthyroid.

\section{Sex Distribution}

Of the 90 patients included in the study, $86.7 \%$ (78) are females and $13.3 \%$ (12) are males.

\section{Hypothyroidism}

Sex Distribution among Hypothyroid Patients

Out of 81 hypothyroid patients in our study, $87.6 \%$ (71) are female and $12.3 \%$ (10) are male patients.

\section{Age Distribution among Hypothyroid Patients}

Maximum number of patients were in the age group $31-40$ yrs. (30.8\%) and minimum in $1-10$ yrs. (1.23\%). The age group ranged from 8 - 66 yrs. and mean age of all the patients included in the study was 35.5 yrs. Mean duration of the disease was 3.35 years. Details of age distribution among hypothyroid patients is shown in Table 1.

\begin{tabular}{|c|c|c|}
\hline Age Group & No. of Patients & \% of Patients \\
\hline $1-10$ yrs. & 1 & $1.23 \%$ \\
\hline $11-20$ yrs. & 10 & $12.3 \%$ \\
\hline $21-30$ yrs. & 21 & $25.9 \%$ \\
\hline $31-40$ yrs. & 25 & $30.8 \%$ \\
\hline $41-50$ yrs. & 16 & $19.7 \%$ \\
\hline $51-60$ yrs. & 5 & $6.2 \%$ \\
\hline $61-70$ yrs. & 3 & $3.7 \%$ \\
\hline Total & $\mathbf{8 1}$ & $\mathbf{1 0 0 \%}$ \\
\hline Table 1. Age Distribution among Hypothyroid Patients \\
\hline
\end{tabular}

\section{General Symptomatology in Hypothyroidism}

The most common symptom with which hypothyroid patients presented was weight gain, seen in $46.9 \%$ of patients followed by fatigue and muscle weakness seen in $45.6 \%$ of patients. Cold intolerance was noted in $37 \%$ of patients, neck swelling in $27.1 \%$ of patients, menstrual abnormalities in $24.7 \%$ of patients. Change in voice and constipation were noted in $18.5 \%$ of patients, swelling of feet in $16 \%$ of patients and slowness of response in $6.1 \%$ of patients.

\section{Dermatological Symptoms in Hypothyroid Patients}

The most common symptom with which $44.4 \%$ of hypothyroid patients presented was dry skin. Hair fall was the complaint in $43.2 \%$ of patients, itching in $38.2 \%$ patients, facial swelling in $30.8 \%$ of patients and brittle nails in $6.17 \%$ of the patients in our study. Table 2 shows various skin symptomatology among hypothyroid patients.

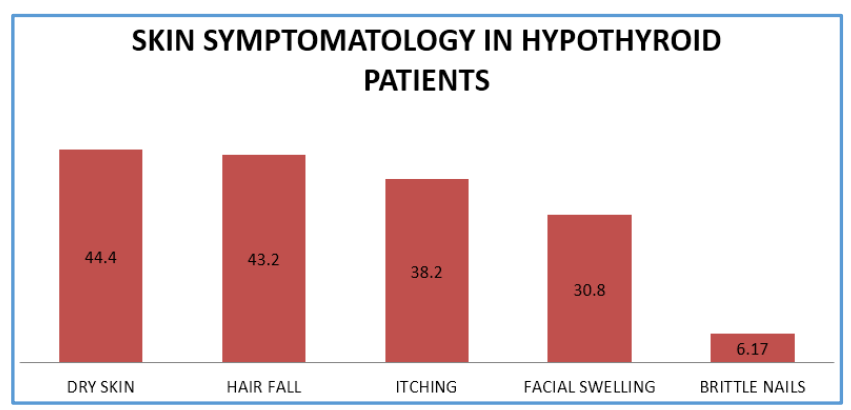

Table 2. Skin Symptomatology among Hypothyroid Patients

Cutaneous Signs in Hypothyroidism
Xerosis with a percentage of $65.43 \%$ was the most common cutaneous manifestation in hypothyroid patients in our study followed by doughy, rough, coarse skin in $49.38 \%$ of patients. Other common dermatologic findings observed in our study are shown in Table 3.

\begin{tabular}{|c|c|c|}
\hline Sign & $\begin{array}{c}\text { No. of } \\
\text { Patients }\end{array}$ & $\begin{array}{c}\% \\
\text { of Patients }\end{array}$ \\
\hline Xerosis & 53 & $65.43 \%$ \\
\hline Ichthyosis & 9 & $11.11 \%$ \\
\hline Doughy, coarse, rough skin & 40 & $49.38 \%$ \\
\hline Cool skin & 15 & $18.51 \%$ \\
\hline Pale skin & 7 & $8.64 \%$ \\
\hline Carotenemias & 12 & $14.81 \%$ \\
\hline Myxoedema & 13 & $16.04 \%$ \\
\hline Facial changes & 14 & $17.28 \%$ \\
\hline Swelling of feet & 18 & $22.22 \%$ \\
\hline Keratoderma & 15 & $18.51 \%$ \\
\hline Hyperpigmentation & 18 & $22.22 \%$ \\
\hline Bruising & 2 & $2.46 \%$ \\
\hline \multicolumn{3}{|c|}{$\begin{array}{l}\text { Table 3. Dermatologic Findings } \\
\text { among Hypothyroid Patients }\end{array}$} \\
\hline
\end{tabular}

Hair and Nail Changes in Hypothyroidism

Diffuse non-scarring alopecia with a percentage of $43.2 \%$ and longitudinal striations with a percentage of $24.69 \%$ were the most common hair and nail changes noted in our study. Other hair and nail changes are shown in Table 4.

\begin{tabular}{|c|c|c|}
\hline Sign & $\begin{array}{c}\text { Number of } \\
\text { Patients }\end{array}$ & $\begin{array}{c}\text { Percentage } \\
\text { of Patients }\end{array}$ \\
\hline Dry, coarse hair & 17 & $20.98 \%$ \\
\hline Brittle hair & 10 & $12.34 \%$ \\
\hline $\begin{array}{c}\text { Diffuse non-scarring } \\
\text { alopecia }\end{array}$ & 35 & $43.20 \%$ \\
\hline Alopecia areata & 2 & $2.46 \%$ \\
\hline Madarosis & 3 & $3.70 \%$ \\
\hline Brittle nails & 4 & $4.93 \%$ \\
\hline Longitudinal striations & 20 & $24.69 \%$ \\
\hline \multicolumn{2}{|c|}{ Onycholysis } & 5 \\
\hline \multicolumn{2}{|c|}{ Table 4. Hair and Nail Changes } \\
among Hypothyroid Patients \\
\hline
\end{tabular}

\section{Dermatologic Associations of Hypothyroidism}

Urticaria seen in $14.81 \%$ of the patients was the most common dermatological disease associated with hypothyroidism in our study. Lichen planus and psoriasis each were noted in $7.40 \%$ of the cases. Vitiligo was noted in $8.64 \%$ of the cases and PMLE in $4.93 \%$ of cases. Other common dermatological associations are shown in Table 5.

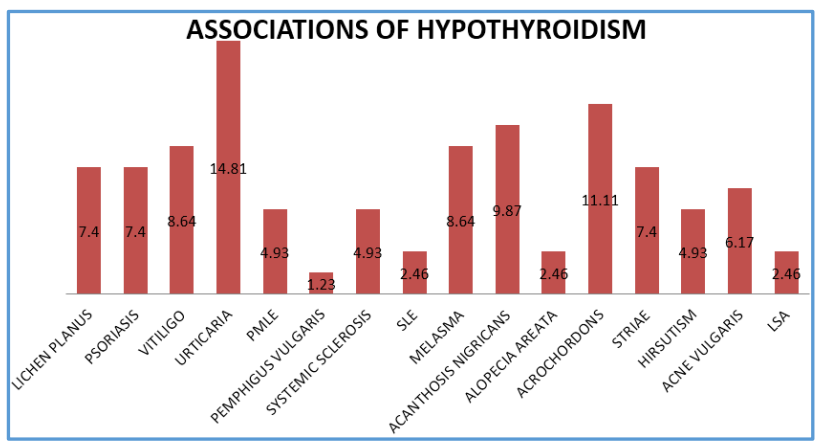

Table 5. Table showing various dermatologic Associations among Hypothyroid Patients 
Other associated disorders were steatocystoma multiplex, cutaneous amyloidosis, idiopathic guttate hypomelanosis, infraorbital melanosis, prurigo simplex, stasis dermatitis, dermatomyositis, bullous pemphigoid, morphea noted each in $1.23 \%$ of hypothyroid patients. Pityriasis versicolor was noted in $6.17 \%$, tinea cruris in $2.46 \%$, genital herpes in $1.23 \%$ and vulvovaginal candidiasis in $8.64 \%$ of the cases. Vitiligo and psoriasis were present in one patient. Psoriasis and urticaria were present in one patient of our study.

\section{Hyperthyroidism}

Of the total 90 patients included in the study, 9 patients were hyperthyroid. Males constituted $78 \%$ and females constituted $22 \%$ in our study with male-to-female ratio of 2:7.

\section{Age Distribution among Hyperthyroid Patients}

Maximum number $(33.3 \%)$ of hyperthyroid patients in our study were in the age group 31 - 40 yrs. Mean age of the patients was $37.4 \mathrm{yrs}$. and range of their age was $19-60 \mathrm{yrs}$. Mean duration of disease is 4 yrs. with shortest duration being 10 days and longest duration being 11 years. Detailed age distribution of hyperthyroid patients is shown in Table 6.

\begin{tabular}{|c|c|c|}
\hline Age & No. of Patients & No. of Patients \\
\hline $11-20$ yrs. & 1 & $11.1 \%$ \\
\hline $21-30$ yrs. & 3 & $33.3 \%$ \\
\hline $31-40$ yrs. & 2 & $22.2 \%$ \\
\hline $41-50$ yrs. & 1 & $11.1 \%$ \\
\hline $51-60$ yrs. & 2 & $22.2 \%$ \\
\hline Total & $\mathbf{9}$ & $\mathbf{1 0 0} \%$ \\
\hline \multicolumn{2}{|c|}{ Table 6. Showing Age Distribution } \\
among Hyperthyroid Patients \\
\hline
\end{tabular}

\section{Symptoms in Hyperthyroid Patients}

Heat intolerance and increased sweating seen in $66.6 \%$ of patients was the most common symptom noticed in hyperthyroid patients included in the study. Weight loss in $55.5 \%$, diarrhoea and palpitations each in $22.2 \%$, neck swelling in $55.5 \%$, hair loss in $44.4 \%$, tremors in $33.3 \%$, fatigue in $55.5 \%$, change in voice in $44.4 \%$, shortness of breath in $55.5 \%$ and menstrual disturbances were complained by $22.2 \%$ of the hyperthyroid patients.

\section{Cutaneous Signs in Hyperthyroid Patients}

Warm skin, soft velvety skin and hyperpigmentation each were noted in $33.33 \%$ of hyperthyroid patients. Diffuse alopecia, soft fine hair each were noted in $44.44 \%$ of the patients. Nail changes like brittle, fast growing nails were observed in $55.55 \%$ of the patients. Other dermatologic findings among hyperthyroid patients are shown in Table 7.

\begin{tabular}{|c|c|c|}
\hline Sign & No. of Patients & \% of Patients \\
\hline Exophthalmos & 2 & $22.22 \%$ \\
\hline Hyperhidrosis & 2 & $22.22 \%$ \\
\hline Warm skin & 3 & $33.33 \%$ \\
\hline Soft velvety skin & 3 & $33.33 \%$ \\
\hline Hyperpigmentation & 3 & $33.33 \%$ \\
\hline Diffuse alopecia & 4 & $44.44 \%$ \\
\hline Soft fine hair & 4 & $44.44 \%$ \\
\hline Nail changes & 5 & $55.55 \%$ \\
\hline Palmar erythema & 1 & $11.11 \%$ \\
\hline \multicolumn{2}{|c|}{ Table 7. Table showing Cutaneous Findings } \\
among Hyperthyroid Patients \\
\hline \multicolumn{3}{|c}{} \\
\hline
\end{tabular}

\section{Dermatological Associations of Hyperthyroidism}

Psoriasis and urticaria each were noted in $22.22 \%$ of the patients. Melasma was observed in $11.11 \%$ of hyperthyroid patients in our study.

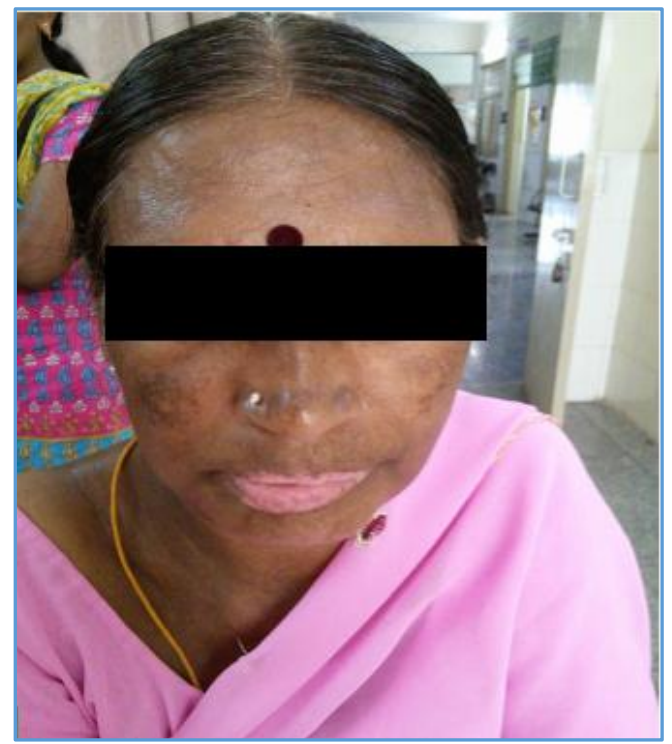

Vitiligo in a Hypothyroid Patient

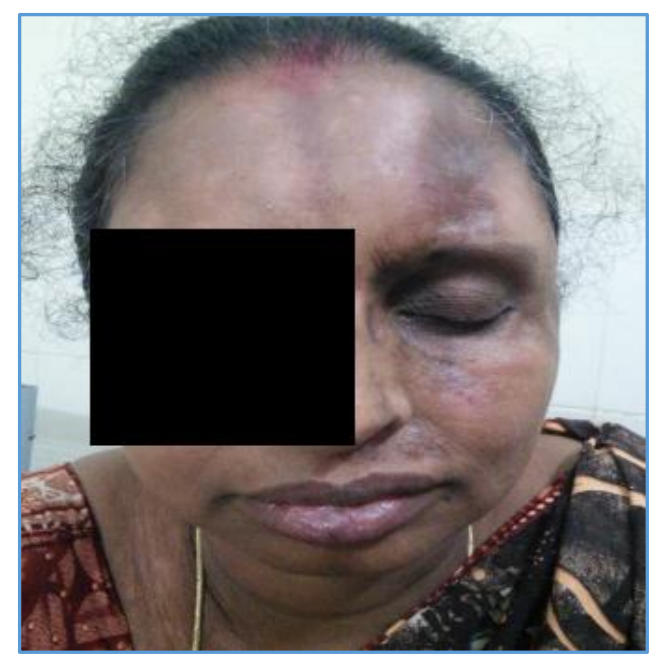

Morphea in a Hypothyroid Patient

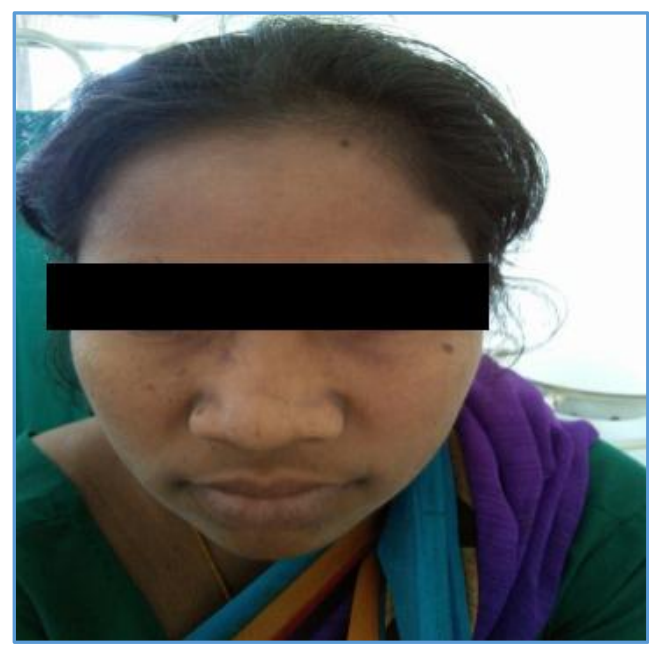

Dull Looking Face of a Hypothyroid Patient 




Xerosis in the Above Patient



Exophthalmos in a Hyperthyroid Patient

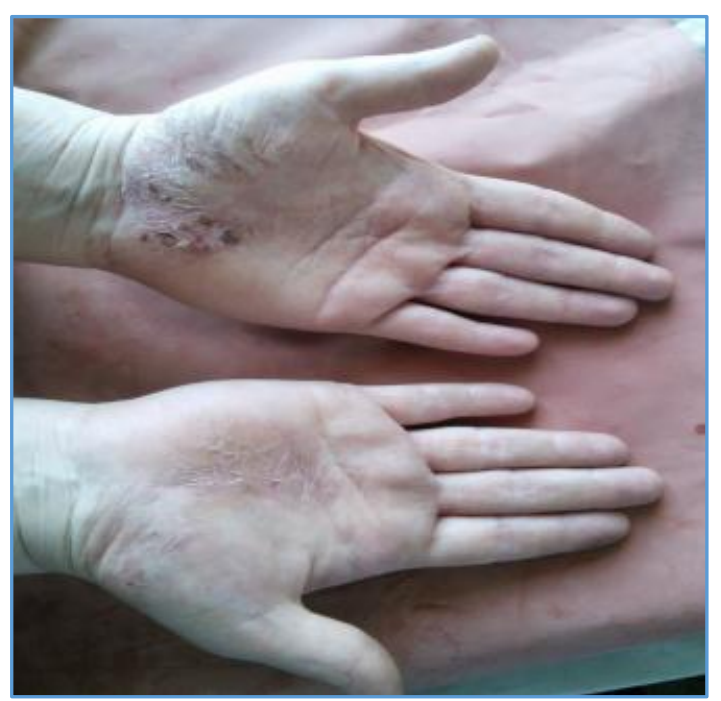

Psoriasis in a Hypothyroid Patient

\section{DISCUSSION}

Out of a total of 90 patients included in our study, 90\% were hypothyroid and 10\% were hyperthyroid. Male-to-female ratio among hypothyroid in our study was 1:7.1. This is in accordance to study done by A. Dogra et $\mathrm{al}^{1}$ (1:7). The female preponderance may be due to increased association of autoimmune disorders including autoimmune thyroiditis in females. ${ }^{2}$ The effects of female gonadal hormones and $\mathrm{X}$ chromosome inactivation on thyroid gland and immune system greatly contribute to the female predilection of autoimmune disorders. The direct actions of oestrogen on the thyroid tissue contribute to the development of thyroid goitre, nodule and cancer in women. ${ }^{3}$

Commonest age group affected in our study was $31-40$ yrs. followed by 21 - 30 yrs. This is similar to the study done by Joan Felicita Samson et al, ${ }^{4}$ which showed a peak prevalence of thyroid disorders among 31 - 40 yrs. and Aditi Jamwal et al, ${ }^{2}$ which had a maximum number of cases between 31 - 50 years of age.

Weight gain, fatigue and muscle weakness were the common general symptoms noted among hypothyroid patients in our study with percentages of $46.9 \%$ and $45.6 \%$ respectively. Weight gain with a percentage of $71.85 \%$ was the commonest symptom in study done by A. Dogra et al. ${ }^{1}$

Dry skin was the commonest cutaneous complaint seen in $44.4 \%$ of hypothyroid patients in our study, which is relatively lower when compared to other studies. Depletion of T3 results in elevated levels of transglutaminase, which is involved in the formation of the cornified envelope. T3 depleted keratinocytes also have diminished levels of plasminogen activator, an enzyme implicated in the corneocyte shedding process making the skin appear dry, coarse. ${ }^{5}$

Hair fall was the second most common complaint in our study showing a percentage of $43.2 \%$ among hypothyroid patients. This is similar to the results of studies by Mohammad Abid Keen et al $(42.6 \%)^{6}$ and Aditi Jamwal et al (48\%). ${ }^{2}$ The effect of thyroid hormones on hair cycle is thought to be responsible for hair fall in hypothyroidism. There occurs an increased number of hair in telogen phase causing hair fall, that is reversible with thyroid hormone replacement.

Xerosis with a percentage of $65.43 \%$ was the commonest cutaneous manifestation among hypothyroid patients included in our study. Xerosis was seen in $100 \%$ of patients, was in study done by Neeraja Puri et al. Xerosis in hypothyroidism may be attributed to a change in skin texture and poor hydration of the stratum corneum. ${ }^{7}$

Dry, rough, coarse skin was recorded in $49.38 \%$ of patients in our study, which is similar to study by Aditi Jamwal et al (47\%). Dry, rough, cool and scaly skin can be explained by decreased cutaneous metabolism, reduced secretion of sweat and sebaceous glands, vasoconstriction, thinning of epidermis and hyperkeratosis of stratum corneum as discussed by Aditi Jamwal et al. 8

Hyperpigmentation was noted in $46 \%$ of hypothyroid patients by Aditi Jamwal et $\mathrm{al}^{2}$ whereas our study revealed hyperpigmentation only in $22.2 \%$. Hyperpigmentation, in hypothyroidism may be due to increased release of pituitary adrenocorticotropic hormone, compensating for the cortical insufficiency secondary to severe longstanding hypothyroidism. 9,10 
Palmoplantar keratoderma was observed in $18.51 \%$ of hypothyroid patients in our study. Heymann WR in his article proposed that hypohidrosis, accompanied by diminished epidermal sterol biosynthesis may lead to acquired palmoplantar keratoderma in hypothyroidism.11 A common feature of this acquired palmoplantar keratoderma is that lack of response to topical corticosteroids, but a total response to thyroid hormone replacement.

Characteristic facial changes were observed in $17.28 \%$ of the patients in our study. This includes a dull look with swollen lips, broad nose, macroglossia and puffy drooping eyelids.

Myxoedema was noted in $16.04 \%$ of hypothyroid patients in our study, whereas other studies revealed a wide varying results between $3.1 \%$ as observed by A. Dogra et al ${ }^{1}$ and $25 \%$ as recorded by Joan Felicita Samson et al.4 Myxoedema, a classic cutaneous sign in hypothyroidism, occurs due to deposition of glycosaminoglycans in the dermis that alter refraction of light making the skin appear pale as discussed by Kasumagic-Halilovic E. 12

Pallor of skin was observed among 8.64\% of hypothyroid patients included in our study. This complexion in hypothyroidism is described as 'strawberry and cream,' because general pallor is associated with erythema of cheeks. It develops as a normal response to decreased oxygen requirement and results in decrease in erythropoietin and erythropoiesis with a slight bone marrow hypoplasia.13 Another reason for pallor is cutaneous vasoconstriction ${ }^{8}$ and anaemia.

Diffuse, non-scarring alopecia was the most common hair change observed in hypothyroid patients included in our study with a percentage of $43.2 \%$. In study by A. Dogra et al, ${ }^{1}$ telogen effluvium was noted in $40.62 \% ; 33.3 \%$ had diffuse hair loss in study done by Neeraja Puri et al. Feingold KR in his article proposed that alopecia of hypothyroidism is mediated via hormone effect on the initiation as well as duration of hair growth. Normal telogen-anagen hair relationships were restored with thyroid hormone replacements. ${ }^{5}$

Prevalence of nail changes among hypothyroid patients varied from $3.12 \%$ in study done by A. Dogra et al ${ }^{1}$ to $84 \%$ in study by N. Nagaraj et al. ${ }^{14}$ Various nail changes observed among hypothyroid patients in different studies include brittle nails, loss of cuticle, periungual telangiectasia, onycholysis, vertical striations. Nail changes seen in hypothyroid patients in our study were longitudinal striations in $24.69 \%$, onycholysis in $6.17 \%$ and brittle nails in $4.93 \%$ of patients. Severe case reports have demonstrated onycholysis as the presenting symptom of undiagnosed hypothyroidism. Although onycholysis may have many aetiologies, patients with unexplained onycholysis should be screened for asymptomatic thyroid disease. The mechanism of nail changes in thyroid disease may be due to the effect of thyroid hormone on cell metabolism and mitosis and in most cases nail alteration is completely reversible after adequate treatment of the underlying thyroid disorder. ${ }^{5}$

\section{Hyperthyroidism}

Male-to-female ratio among hyperthyroid patients in present study is $1: 3.5$. The ratio is $1: 3.3$ in a study by Ramanathan et al and 1:2.27 which is in concordance to our study.

Heat intolerance and increased sweating with a percentage of $66.6 \%$ was the most common symptom noticed in hyperthyroid patients included in the present study, whereas increased skin temperature with a percentage of $92 \%$ was the commonest complaint among hyperthyroid patients in a study by Nabi $\mathrm{H}$ et al. ${ }^{15}$

Warm skin, soft velvety skin was noted in $33.33 \%$ of hyperthyroid patients in our study, whereas $85.7 \%$ had the same finding in study by Neeraja Puri et al. T3 inhibits vascular smooth muscle contractility, thus causing vasodilation. T3 also suppresses vascular smooth muscle cell proliferation by inhibiting angiotensin mediated activation of cyclic adenosine monophosphate (C-AMP) response binding protein. ${ }^{16}$ The above vascular changes together may account for warm skin in hyperthyroidism.

Exophthalmos was noted in $22.2 \%$ of patients in our study. The aetiology of the thyroid-related orbitopathy is an autoimmune-mediated inflammatory process of the orbital tissues, predominantly affecting the fat and the extraocular muscles.

Diffuse alopecia and soft fine hair, each were noted in $44.44 \%$ of the patients. The effect of thyroid hormone on hair growth is unclear. In vitro studies suggest increased hair growth rate in thyrotoxicosis. DNA flow cytometry studies of dissected anagen hairs from thyrotoxic patients (compared with follicles taken from euthyroid controls) demonstrated a $30 \%$ increase in the $\mathrm{S}$ and $\mathrm{G} 2+\mathrm{M}$ phases of the cell cycle.

Nail changes like brittle, fast growing nails were observed in $55.55 \%$ of the patients, while none had thyroid acropachy in our study. Onycholysis and Plummer's nails were noted in $28.6 \%$ of patients in study by Neeraja Puri et al.

\section{Associations}

Urticaria, with a percentage of 14.81 , was the most common dermatological disease associated with hypothyroid patients in our study. $22.2 \%$ of hyperthyroid patients had urticaria in the present study. Urticaria was the commonest association with thyroid disorders in study by Mohammad Abid Keen et $\mathrm{al}^{6}$ and $\mathrm{N}$. Nagaraj et $\mathrm{al}^{14}$ with a percentage of $13.04 \%$ and $28.5 \%$ respectively. Patients with coexistent thyroid autoimmunity and CU have a more severe and prolonged course of urticaria than those without thyroid autoimmunity. The risk of developing angioedema in patients with thyroid autoimmunity and CU is estimated to be 16.2 times greater than those with CU without thyroid autoimmunity. Warren $\mathrm{R}$ Heymann ${ }^{17}$ has stated that there is a clustering of thyroid microsomal antibodies in patients with positive autologous serum test, although it is unlikely that thyroid hormone itself has any in vivo effect on the cutaneous vascular response to histamine and on mast cell releasability. ${ }^{18}$

Acrochordons were noted in $11.11 \%$ of patients in our study. Rezzonico et al concluded that individuals with skin tags have high prevalence of thyroid nodules and thyroid with increased volume. This is because skin tags and thyroid changes may be associated with high levels of circulating insulin. ${ }^{19}$

Acanthosis nigricans was observed in $8.97 \%$ of subjects in our study. An article by Matsuoka et al concluded that hypothyroidism may be associated with acanthosis nigricans, that hyperinsulinaemia is a regular correlate of the skin disorder and that treatment of hypothyroidism does not resolve the hyperinsulinaemia or acanthosis nigricans. ${ }^{11}$

Vitiligo was noted in $8.64 \%$ of patients in our study and among $8 \%$ of hypothyroid patients in study done by Neeraja Puri et al. 
AITD is approximately three times more prevalent in adults with vitiligo than in general population. An article by KVT Gopal et al suggests a higher prevalence of hypothyroidism, diabetes mellitus or both in generalised or acrofacial vitiligo compared to localised vitiligo suggesting that there is a positive correlation between the existence of other autoimmune diseases and the severity of vitiligo. KVT Gopal in his article also suggests that paediatric patients with vitiligo should be routinely subjected to thyroid screening as the diagnosis of autoimmune thyroiditis is particularly important in this age group to avoid the negative impact of hypothyroidism on growth and health status. ${ }^{20}$

Psoriasis was observed in $7.4 \%$ hypothyroid and $22.2 \%$ in hyperthyroid patients in our study. The association between thyroid disorders and psoriasis was not statistically significant in study by Gul U and Gonul M.21 Some authors like Dr. Wu supported the association. 22 However, the association between psoriatic arthritis and autoimmune thyroid disorders has been substantiated in many studies.

Lichen planus was noticed among 7.4\% of hypothyroid patients in our study. Prevalence of lichen planus was $0.86 \%$ in study by Mohammad Abid Keen et al, ${ }^{6}$ whereas 3.17\% had lichen planus in a study by Haritha et al. Our study showed a greater prevalence of lichen planus among hypothyroid subjects. Studies done to test the association between lichen planus and thyroid dysfunction by Siponen et al and Sheikh Manzoor et al revealed that a significant percentage of patients with lichen planus, both oral and cutaneous had associated thyroid gland dysfunction. ${ }^{23}$

Polymorphic light eruption was recorded among $4.93 \%$ of hypothyroid patients in our study, whereas only $0.86 \%$ of hypothyroid patients had PMLE in study done by Mohammad Abid Keen et al. ${ }^{6}$ An article on association of polymorphic light eruption and autoimmune thyroiditis by KA Seetharam, K Sridevi revealed a significant statistical relation between PMLE and autoimmune thyroid disease and they also stated that the relation between two diseases is immune dysfunction causing hypersensitivity in PMLE and antibody generation in thyroid disease.

Alopecia areata was recorded among $2.46 \%$ of hypothyroid patients in our study, whereas $3.12 \%$ in study by A. Dogra et al $4 \%$ in a study by Neeraja Puri et al. In their review of thyroid disease and alopecia areata in children and adolescents, Kurtwv and Iliev identified autoimmune thyroid disorders in $47.8 \%$ of their study population. They recommended thyroid screening at the time of diagnosis of alopecia areata and twice yearly thereafter. Patients with alopecia totalis and alopecia universalis are more likely to have thyroid disease than patients with patchy alopecia areata. ${ }^{24,25}$

Morphea, a form of localised scleroderma was noted in $1.23 \%$ of hypothyroid patients in our study. Hyun Jeong et al in their presentation of two patients with morphea and autoimmune thyroid disorders recommend that patients with morphea undergo thyroid screening as described for hypothyroid patients. ${ }^{26}$

\section{CONCLUSION}

With our study, it could be concluded that interaction between thyroid gland and skin is dynamic and complex. Both hypothyroidism and hyperthyroidism are associated with a wide variety of cutaneous manifestations.
A better understanding of these features help us not only to diagnose underlying thyroid abnormality, but also to monitor response of cutaneous features with treatment.

\section{REFERENCES}

[1] Dogra A, Dua A, Singh P. Thyroid and skin. Indian J Dermatology 2006;51(2):96-9.

[2] Jamwal A, Sharma A, Rather PA. Cutaneous manifestations of hypothyroidism: prospective hospital based clinical study. J Adv Med Dent Scie 2013;1(2):5-12.

[3] Li H, Li J. Thyroid disorders in women. Minerva Med 2015;106(2):109-14.

[4] Samson JF, Mathew PS, Libu GK, et al. A study of the cutaneous manifestations of hypothyroidism and hyperthyroidism. Kerala Medical Journal 2011:52-4.

[5] Safer JD. Thyroid hormone action on skin. Dermatoendocrinol 2011;3(3):211- 5.

[6] Keen MA, Hassan I, Bhat MH. A clinical study of the cutaneous manifestations of hypothyroidism in Kashmir valley. Indian J Dermatol 2013;58(4):326.

[7] Hierholzer K, Finke R. Myxedema. Kidney Int Suppl 1997;59:S82-S89.

[8] Tonacchera M, Chiovato L, Pinchera A. Clinical assessment and systemic manifestations of hypothyroidism. Oxford Textbook of endocrinology and diabetes. $1^{\text {st }}$ edn. Oxford University Press 2002:491-501.

[9] Khopkar U, Pande S. Etiopathogenesis of pruritus due to systemic causes: implications for treatment. Indian J Dermatol Venereol Leprol 2007;73(4):215-7.

[10] Larsen PR, Davies TF, Hay ID. Hypothyroidism and thyroiditis. William's Textbook of endocrinology. 9th edn. Philadelphia: WB Saunders 1998:423-55.

[11] Matsuoka LY, Wortsman J, Gavin JR, et al. Acanthosis nigricans, hypothyroidism and insulin resistance. Am J Med 1986;81(1):58-62.

[12] Kasumagic-Halilovic E. Thyroid autoimmunity in patients with alopecia areata. Acta Dermatovenerol Croat 2008;16(3):123-5.

[13] Wiersinga WM. Hypothyroidism and myxedema coma. Endocrinology $5^{\text {th }}$ edn. 1999:2081-6.

[14] Nagaraj N, Balaji S, Singla M, et al. Dermatological manifestations in autoimmune thyroid disorders. BMC Proceedings 2012;6(Suppl 4):039.

[15] Nabi H, Hussain I, Aamir S, et al. Cutaneous manifestations of hyperthyroidism - a study of 50 cases from Lahore, Pakistan. JCPSP 2001;11(7):427-30.

[16] Fukuyama K, Ichiki T, Imayama I, et al. Thyroid hormone inhibits vascular remodeling through suppression of cAMP response element binding protein activity. Arterioscler Thromb Vasc Biol 2006;26(9):2049-55.

[17] Heymann WR. Chronic urticaria and angioedema associated with thyroid autoimmunity: review and therapeutic implications. J Am Acad Dermatol 1999;40(2 Pt 1):229-32.

[18] Rumbyrt JS, Katz JL, Schocket AL. Resolution of chronic urticaria in patients with thyroid autommunity. J Allergy Clin Immunol 1995;96(6 Pt 1):901-5. 
[19] Rezzonico J, Rezzonico M, Pusiol E, et al. High prevalence of thyroid nodules in patients with acrochordons (skin tags). Possible role of insulinresistance. Medicina (B Aires) 2009;69(3):302-4.

[20] Gopal K, Rao GR, Kumar YH. Increased prevalence of thyroid dysfunction and diabetes mellitus in Indian vitiligo patients: a case control study. Indian Dermatol Online J 2014;5(4):456-60.

[21] Gul U, Gonul M, Kaya I, et al. Autoimmune thyroid disorders in patients with psoriasis. Eur J Dermatol 2009;19(3):221-3.

[22] Wu JJ, Nguyen TU, Poon KY, et al. The association of psoriasis with autoimmune diseases. J Am Acad Dermatol 2012;67(5):924-30.
[23] Manzoor S, Qayoom S, Sultan J, et al. Thyroid profile in lichen planus patients from Kashmir valley. Egyptian Dermatology Online Journal 2013;9(1):1-5.

[24] Goh C, Finkel M, Christos PJ, et al. Profile of 513 patients with alopecia areata: associations of disease subtypes with atopy, autoimmune disease and positive family history. J Eur Acad Dermatol Venereol 2006;20(9):1055-60.

[25] Hordinsky M, Ericson M. Autoimmunity: alopecia areata. J Investig Dermatol Symp Proc 2004;9(1):73-8.

[26] Lee HJ, Kim MY, Ha SJ, et al. Two cases of morphea associated with Hashimoto's thyroiditis. Acta Derm Venereol 2002;82(1):58-9. 